\title{
The Design of Digital Liquid Density Meter Based on Arduino
}

\author{
Prisma Megantoro ${ }^{1}$, Andrei Widjanarko ${ }^{2}$, Robbi Rahim ${ }^{3}$, Kunal Kunal $^{4}$, Afif Zuhri Arfianto ${ }^{5}$ \\ ${ }^{1,2}$ Department of Electrical Engineering and Informatics, Universitas Gadjah Mada, Yogyakarta, Indonesia \\ ${ }^{3}$ School of Computer and Communication Engineering, University of Malaysia Perlis, Malaysia \\ ${ }^{4}$ School of Information, Communication \& Technology, Indraprastha University, Delhi, India \\ ${ }^{5}$ Politeknik Perkapalan Negeri Surabaya, Surabaya, Indonesia \\ 1'megantoro.prisma@gmail.com, ${ }^{2}$ widjanarkoandrei@gmail.com, ${ }^{3}$ robbi@ieee.com, ${ }^{4}$ Kunal.karn007@gmail.com, \\ ${ }^{5}$ afifzuhri@ieee.org
}

\begin{abstract}
A measure of liquid thickness is needed to make a dough or formula for medicinal syrup. The tools to measure the thickness available in the market are analog that is less accurate and precision. To overcome these problems, digital density measuring devices are needed. The limitation of the digital density meter, especially liquid, urges the author to carry out further research on the digitization of this measuring instrument. This research aims to make a digital density meter for liquid matter with a high level of measurement accuracy, as the reference measurement study for liquid density in digital form. The instrument was designed using the load cell method as the main sensor. It was also equipped with a DS18B20 waterresistant temperature sensor to measure the temperature of the liquid. The data were analyzed to obtain the accuracy and error of the liquid density measurement from the density meter. The liquid samples used for research were Pertamax, solar, and water. Sample accuracy and error measurement results were 99.83 percent and 0.17 percent respectively for Pertamax, 99.63 percent and 0.37 percent for solar and 99.46 percent and 0.54 percent for water. The measured density value was finally shown on the 16x2 LCD.
\end{abstract}

\section{Keywords—LLad cell, DS18B20 sensor, Arduino}

\section{INTRODUCTION}

All aspects of measurement require accurate measurement devices to estimate the quantities, such as hydrometers, thermometers, and viscometer within the laboratory scope. Until now, the density meter for liquid is still in analog form on a laboratory scale. Analog measuring tools contribute to the uncertainty of measurement caused by human error because each person's reading is different. To overcome this problem, the authors are interested in designing a measuring instrument as a final project entitled "Design of Arduino-Based Digital Liquid Density meter" which can later measure the density or density value of some liquid by detecting the mass tested with a certain volume as a constant, then displaying the measurement results in digital form.

Several researchers have conducted research on liquid density meters. Popa and Pantelimon investigated the equation method to measure liquid density in the VC1005 volume comparator [1]. The method measured liquid density with a volume comparator automatically carried out simultaneously with measurements. Kazys investigated ultrasonic density measurement of melted polymers under extreme conditions [2]. The aim of his work was to develop and investigate ultrasonic densities according to polymer melt measurement techniques. Heinisch investigated the characterization and calibration of U-shaped mass density and viscosity sensors with analytical modeling approaches [3]. His work was about resonant viscosity and mass density sensors based on o-shaped oscillations of structures that operate at their fundamental resonant frequencies.

Roy investigated LabVIEW implementation of liquid density measurement using ultrasonic transducers [4]. The LABVIEW platform was used to calculate the travel time of ultrasonic waves between the transmitter to the receiver. Kielczynski examined the density and viscosity of fluid determination using the inverse method for propagation of the Love wave [5]. It aimed to establish an inversion of procedures for determining the viscosity and density of fluids simultaneously. Manzaneque investigated density-viscosity sensor based on the piezoelectric MEMS resonator and oscillator circuit [6]. The sensitivity involved was evaluated, along with the resolution for density and viscosity, below $4.09 \mathrm{~g} / \mathrm{ml}$ and $2.07 \cdot 10-3 \mathrm{mPa} \cdot \mathrm{s}$ respectively.

Latifa examined the dynamic behavior and density of the polymer/liquid crystal mixture prepared by polymerizationinduced phase separation [7]. The researcher investigated the dynamic behavior and density of PDLCs (Polymer Dispersed Liquid Crystals) films. Antlinger studied ultrasonic piezoelectric resonator tubes for sensing physical fluid properties [8]. Ultrasonic sensors are very suitable for the determination of physical fluid parameters such as mass, sound velocity, and viscosity (longitudinal). Maroufi and Shamshirsaz studied PZT Sensor Resonant Behavior in Liquids Using the PSO Method [9]. Piezoelectric-excited resonant millimeter size Cantilevers (PEMC) has attracted the interest of many researchers in applications such as fluid levels and density sensing.

Heinisch investigated higher mode excitation of resonant mass density and viscosity sensors [10]. The application of resonance devices to mass density and sensing by evaluating changes in resonance quality factors and frequency after immersion in liquid samples has been reported in the literature with an increasing number of publications in recent years. Park and Kim High studied accuracy pressure type liquid level measurement system that is able to measure 
density [11]. The system consisted of liquid storage tank and a sensor module for measuring fluid levels. Lamberti examined resonance sensors for bimorph piezoelectric based liquid density measurement [12]. Density is a characteristic of a substance related to its mass and volume. Online density sensors play an important role in several industrial applications, for example in monitoring liquid products.

Souza, Carvalho, and Canuto examined an invariant density and temperature method of measuring Matheus liquid displacer-type levels was examined [13]. The method used the ratio between buoyancy measured by two shifters and two load cells to make it independent and, as a consequence, the temperature does not change. Schut investigated fully integrated flow, pressure, density, and mass viscosity sensors for liquids and gases [14]. The model of the HagenPoiseuillef was for equation liquids, while for gases, a more complicated model was derived, taking into account compressibility and additional pressure loss due to channel geometry. Sanchez-Diaz examined the Bernoulli-Euler modeling of submerged beams for measurement of the container symmetry parameters [15]. Measurement of liquid parameters in containers such as level, density, and viscosity is a widely studied field because of its relevance in various industrial fields.

Sensing density fluid using PMUT was investigated by Roy [16]. It could find applications in a variety of micro and macro systems by tracking the densities. Cabaleiro conducted research on the electrification of fluid flow in rectangular channels in different theoretical models [17]. Different theoretical models were explained and compared. For all models, it was assumed that the flow and diffuse layers were fully developed. Gonzalez investigated viscosity and density of rapid downhole fluid using the oscillating alone tuning fork device was investigated [18]. The ability to characterize fluids while being produced is very important for reservoir management in the oil industry. Real-time information about changes in flow characteristics and fluid composition during production requires downhole (or surface) measurements that are able to investigate these properties.

Based on the background of the research, the paper is presented. It is different from the papers of the other researchers. Previous studies used ultrasonic sensors to determine the density of liquid types, while this research used load cell sensors to determine the specific gravity of fluids. Arduino Uno R3 is used as a microcontroller base because the programming language is easy to understand. Besides, the open-source nature of Arduino Uno R3 makes it easier for beginners to learn about programming. The conventional tool used as a comparison is a Pycnometer because it has higher accuracy compared to other conventional density measuring devices. It is hoped that the digitization of this tool will facilitate the users to read the density of liquid substances, and that measurement errors due to human error can be minimized. In the future, this tool can be used as a reference for learning in the field of metrology in the lecture process.

\section{METHOD}

The method used was to weigh the mass of the liquid to be measured using a load cell as a sensor, equipped with a DS18B20 [19]-[21] waterproof temperature sensor to measure the temperature of the liquid. The Arduino [22]-[24] Uno R3 microcontroller was used as a controller in the density meter system and the results were displayed on the $16 \times 2$ LCD in the form of density and liquid temperature. In this research, the first test was performed to determine the characteristics of these sensors so that the microcontroller could be easily formulated. Next, the design of the Arduinobased fluid density measuring tool was to make it look attractive and simple and to make it easier to read and use. After testing, the data retrieval would be performed to compare the data obtained from the tool with the data not used by the tool.

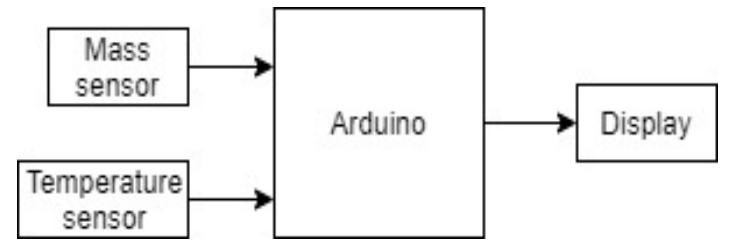

Fig. 1. Measurement system block diagram

The block diagram in Figure 1 illustrates that the system consists of a Load Cell Sensor to weigh water mass and has a maximum weighing capacity of $1 \mathrm{~kg}$, a DS18B20 [25]-[27] sensor that is a waterproof temperature sensor that can be used in the temperature between $-55^{\circ} \mathrm{C}$ to $125^{\circ} \mathrm{C}$, an Arduino [28]-[30] Uno R3 as a circuit controller for the system using the ATMega 328 [31], [32] microcontroller, and a 16x2 LCD to display the measurement results.

\section{Hardware design}

Arduino-based density meter design began with the construction of a system framework and tool design. The method was the weighing method so that a mass sensor, namely a load cell, was needed. The system was also designed with a DS18B20 waterproof temperature sensor to read the temperature of the liquid when measuring the density.

The load cell was used as input and the reading result was processed by the Arduino to be displayed in density value. In the process, an HX711 was needed so that the load cell output could be read and processed by the Arduino. The module also functioned as a load cell output amplifier with an $\mathrm{mV}$ range. The HX711 has 6 input pins used by the load cell were E+, E-, A-, A+, B-, and B+. However, only E+, E-, A-, and A+ were used in this study. Each pin was successively connected by red, black, green, and white wires from the loading cell. Besides, there were four output pins to be connected to the microcontroller, namely GND, DT, SCK, and VCC, successively connected to the Arduino pins. GND was connected to the GND pin, DT pin 3, SCK pin 2, and VCC pin $5 \mathrm{~V}$ to Arduino pin.

Figure 2 displays the hardware and mechanical design of the tool. The DS18B20 temperature sensor consists of red, black and yellow cables. The black wire is ground, red is power supply, and yellow is data. Before being connected to Arduino, a $4.7 \mathrm{k}++$ resistor was installed parallel between the red and yellow wires. The final result was a density value with the liquid temperature reading displayed on the serial monitor and 16x2 LCD. 
(a)

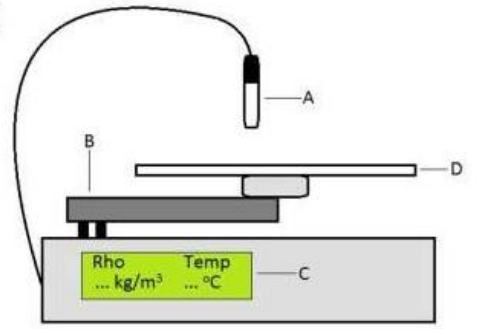

(b)

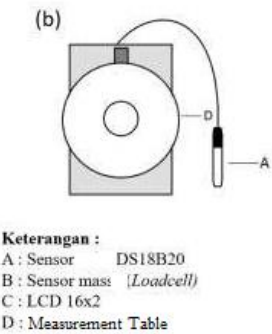

D: Measurement Tabt

Fig. 2. Hardware and mechanical design

Firmware design

A system software design is needed to make the system work well. In this study, the design was a coding program using Arduino Software (IDE) to convert analog output signals of the sensor to other quantities displayed on the LCD. The program started with reading the output signal of the ADC or analog sensor. Next, cell calibration was loaded. By doing so, the calibration factor that needs to be included in the main program was obtained.

In the system, reading was done as much as 40 times with a delay of 2 seconds, then the average calculation of each mass and density value was taken. The results of the average density were then displayed on the LCD with the temperature value read. The display of the measurement results on the LCD density meter was according to the design.

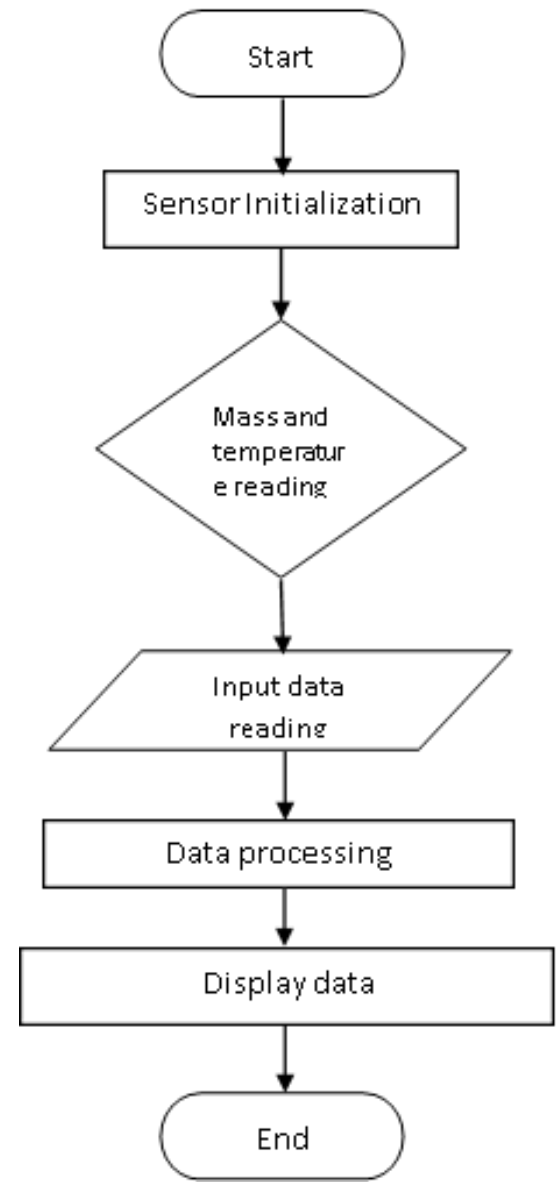

Fig. 3. System workflow

Figure 3 illustrates the system workflow. The process begins with the sensor conditioning, namely load cell and

DS18B20. When the sensor is active, it will read the mass and temperature of the liquid being tested. If the sensor still does not fit in the reading of the magnitude, it needs reconditioning. The liquid mass read can be processed using Arduino to display the density value and temperature of the liquid through the serial monitor and LCD.

\section{Sample test}

Testing using a sample needed to be done to determine the performance of the device by comparing it to the results of measurements of sample density using a calibrated Pycnometer. Preliminary tests were carried out on water samples with volume variations of $10 \mathrm{~mL}, 15 \mathrm{~mL}, 20 \mathrm{~mL}$, and $25 \mathrm{~mL}$. In theory, the density value will not change even though measurements are made for different liquid volumes. However, the best volume conditions from the measurement results that could detect the density approaching the measured density value using a calibrated Pycnometer as a reference would be selected.

The density reading test was also carried out on solar and Pertamax samples with the volume used according to the selected volume. Each test was carried out ten times to determine the average measurement so that the level of error and the accuracy of the test results could be calculated. Physically, the three test samples had different densities and would be proven using a density meter that had been made.

\section{Calculation and analysis}

Equation (1) is an equation to find the density value from the standard Pycnometer tool which is symbolized by $\rho$ in $\mathrm{kg} / \mathrm{m} 3$. M denotes the mass of the liquid in units of $\mathrm{g}, \mathrm{V}$ is the volume capacity of the Pycnometer expressed in $m L .0 .99985$ is obtained from the calculation: [1- (density of air/density of scales)].

$$
\rho=\left(\frac{0.99985 \times M}{v}\right)+0.0012
$$

The density data are taken by ten times the repetition for each liquid, the mean value is searched by,

$$
\bar{\rho}=\frac{\sum_{i=1}^{n} i}{n} .
$$

In (3), $\mathrm{n}$ indicates the number of tests, $\rho i$ indicates the value of the i-th data density in $\mathrm{kg} / \mathrm{m} 3$ and $\bar{\rho}$ is the average value of density in $\mathrm{kg} / \mathrm{m} 3$. Equation 4.3 is used to calculate absolute measurement error the density in percent symbolized by the letter E. $\bar{\rho} \bar{u}$ indicates the average reading of the density using the test density meter in $\mathrm{kg} / \mathrm{m} 3$, whereas $\overline{\rho s}$ shows the average density reading using a calibrated Pycnometer, as standard, in $\mathrm{kg} / \mathrm{m} 3$.

$$
E=\left|\frac{\overline{\rho_{s}}-\bar{\rho}}{\bar{\rho}}\right| x 100 \%
$$

The performance of the tool can be shown by the level of accuracy of the test results that can be searched using,

$$
\text { Accuracy }=(100-E) \% .
$$

\section{IMPLEMENTATION}

The system design that had been made was implemented to become a complete framework. The system implemented needs examination. This chapter will explain the results and 
discussion of the system implementation and testing, namely hardware and software testing.

\section{Load cell calibration test}

Figure 4 showed load cell sensor initially had an incorrect designation, so it was necessary to correct the readings by weighing objects with a known mass, then calibrating using the program on Arduino. By pressing the a, s, d, and f buttons, the calibration factor increased by 10, 100, 1000, and 10000 . While pressing the $\mathrm{z}, \mathrm{x}, \mathrm{c}$, and $\mathrm{v}$ buttons reduced the calibration factor by 10,100, 1000 and 10000. Figure 4 shows the documentation for the load cell calibration test.
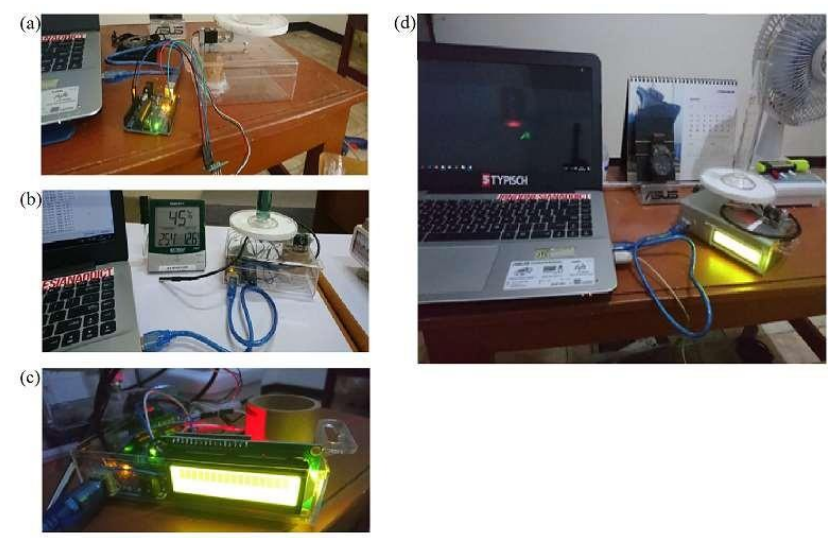

Fig. 4. Hardware test visualization

A beaker glass was used as a measured mass in the load cell calibration experiment. The Load Cell is the main sensor used to make the density meter, therefore it influences the final result of the liquid density. Further testing using Class F scales as the standard was needed to know the value of the load cell mass reading. The results of the load cell sensor test were plotted in the graph. The graph in Figure 5 shows a straight line equation obtained.

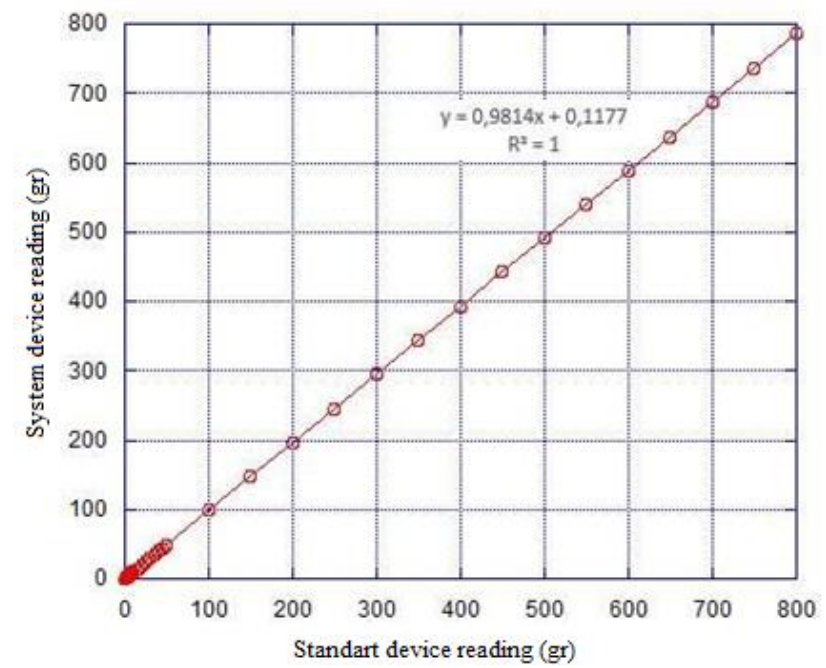

Fig. 5. Comparison between tested system device reading and standard reading for mass measurement

The maximum load cell capacity used was $1 \mathrm{~kg}$, but at the time of the test, a maximum load of $800 \mathrm{~g}$ was given, because the load cell screw had touched the surface of the container underneath. if it were continued up to $1 \mathrm{~kg}$, the reading would be inappropriate. Referring to Table 1 , the biggest error is in
$1 \mathrm{~g}$ of mass, which is 10.5 percent because the maximum load capacity of $1 \mathrm{~kg}$ has a sensitivity that is not fit for measuring $1 \mathrm{~g}$ of mass. Figure 5 shows the linear graph between the mass of the standard scale and the load cell mass designation, accompanied by the linear line equation $y=0.9814 x+0.1177$ with $\mathrm{R} 2=1$. The equation denotes that $\mathrm{y}$ is a function of $\mathrm{x}$, meaning that if $\mathrm{y}$ is the measured mass and $\mathrm{x}$ is the standard mass of the scales (AT), the load cell mass designation (y) will depend on the mass standard of AT (x).

In the equation, there is a value of 0.9814 , also called the slope or gradient of the straight-line function. The slope is positive. It shows a positive relationship as well, meaning that the greater the value of $x$, the greater the value of $y$. Slope also shows the alleged increase in the rate of change in each standard AT, meaning that in addition to the mass of $1 \mathrm{~g}$ the standard scale scales ideally the appointment of a load cell will increase by $0.9814 \mathrm{~g}$. A value of $0.1177 \mathrm{~g}$ is often called an intercept. When there is no loading, the initial designation value is not $0 \mathrm{~g}$ but $0.1177 \mathrm{~g}$. In the straight-line equation above, there is also the value $\mathrm{R} 2=1$, which is the coefficient of determination (KD). Judging from the line equation in Figure 5, it has a KD equal to 1.

\section{Temperature sensor test}

In this study, the temperature measuring instrument used as a reference was a bar thermometer with a reading range of $-10^{\circ} \mathrm{C}$ to $110^{\circ} \mathrm{C}$ to test the designation of the DS18B20 sensor. Figure 6 is a DS18B20 temperature sensor test.

A DS18B20 temperature sensor (waterproof) is a complement to the density meter device which is made to clarify the temperature value of the liquid when the density is measured by the device. The temperature sensor testing was performed by comparing the measurement results from the ROD thermometer which is considered as a standard. The sensor test results were then plotted into the graph, based on the results of the graph obtained straight line equations as shown in Figure 6.

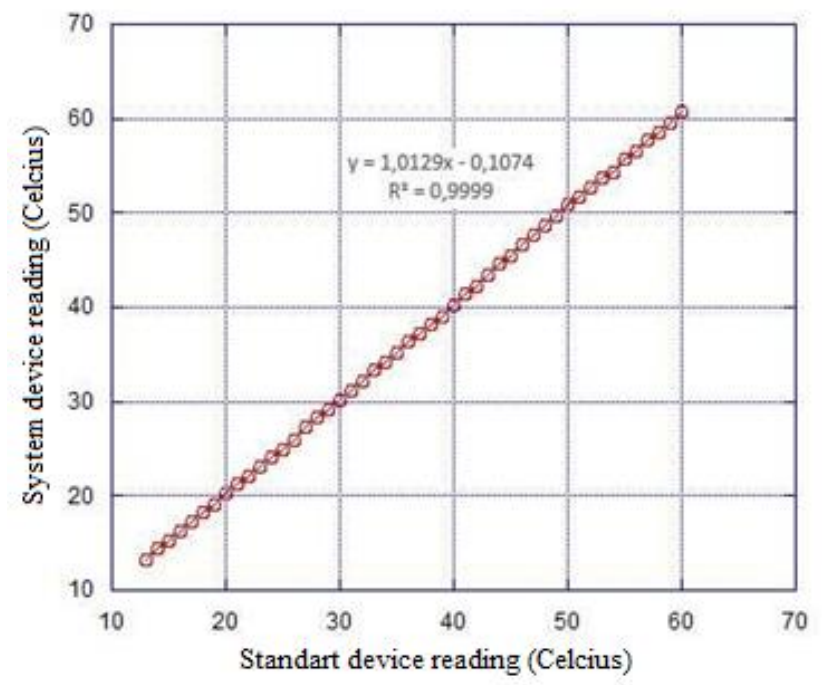

Fig. 6. Comparison graph of tested system device reading against standard reading for temperature measurement

The temperature sensor is ready to be used if the program on the microcontroller is appropriate. Based on the data- 
sheet, the DS18B20 sensor can measure temperatures from$55^{\circ} \mathrm{C}$ to $125^{\circ} \mathrm{C}$. To take the lowest temperature, the author mixed the ice cubes in the water and recorded the temperature drop. In this test, the smallest limit was $13^{\circ} \mathrm{C}$, lower than that the temperature drop that was very slow. The maximum point test was done by mixing hot water little by little until it reached $60^{\circ} \mathrm{C}$, then waiting and reading the temperature drop by degree and comparing the temperature sensor readings as shown in Table 5.2. The lowest point was $13^{\circ} \mathrm{C}$ because the temperature drop below that point was difficult to control. The maximum point was then taken at $60^{\circ} \mathrm{C}$ because it was assumed that there would be no density measurement above that temperature.

The greatest errors from the temperature point based on the test were 13 to 21 degrees Celsius. Looking at Figure 6, which is the comparison graph between the value of the temperature indicated by the standard device and the test tool, there is a straight line equation that needs to be analyzed as well, namely $y=1.0129 x-0.1074$ with $R 2=0.9999$. Similar to the explanation of line equations in load cell testing, in a straight line equation, the temperature test has a positive slope value, which shows a positive relationship, meaning that the higher the value of $x$, the higher the value of $y$. The slope also shows the estimated rate of increase for each temperature change, which means that the temperature changes per degree Celsius read by the standard device ideally indicates that the sensor will increase by $1,0129^{\circ} \mathrm{C}$.

The intercept value of the temperature test line equation was $0.1074^{\circ} \mathrm{C}$. It meant that the initial indication was not $0^{\circ} \mathrm{C}$, but $0.1074^{\circ} \mathrm{C}$. The value of the correlation coefficient of the line equation of 0.99995 was derived from the rooting value of R2. So that, when measured, the value of the proximity of the correlation between setting the temperature by the standard device.

\section{Density Meter Test}

At this stage, the results of the tests were used to measure the density of liquid substances from a density meter with a standard tool, namely a $25 \mathrm{~mL}$ capacity Pycnometer.

Table 1 shows that the density determination by the density meter has a large enough error compared to the results of the standard tool measurements when the density formula in the Arduino program has not been given an enhancement factor. Depending on the error reading by density meter, a factor must be added so that the results of the measurement approach the actual density value. The average value of the three corrections was of $15,36 \mathrm{~kg} / \mathrm{m} 3$. The value entered in the density formulation of the Arduino program as an additional factor.

TABLE I. TEST RESUlT FOR EVERY SAMPLE AND LOOP

\begin{tabular}{|c|c|c|c|c|}
\hline Liquid & I & II & III & $\begin{array}{c}\text { Average } \\
\text { error }\end{array}$ \\
\hline Water & 15.828 & 16.192 & 16.354 & 16.12 \\
\hline Pertamax & 15.904 & 16.74 & 14.339 & 15.66 \\
\hline Solar & 15.28 & 14.497 & 13.0887 & 14.29 \\
\hline \multicolumn{4}{|c|}{ Average error } & 15.36 \\
\hline
\end{tabular}

The error of the density measurement with a mean water sample error was 0.54 percent, the solar sample was 37 percent, and the Pertamax sample was 0.17 percent. Whereas the accuracy of density measurement results by density meter in water samples was 99.46 percent, in solar samples was 99.63 percent, and in the Pertamax sample was 99.83 percent.

\section{CONCLUSIONS}

The findings of this research are: The Liquid Arduinobased density meter shows that the average error of the Pertamax is 0.17 percent, the diesel is 0.37 percent, and the water is 0.54 percent. Whereas the accuracy of the Pertamax is 99.83 percent, the diesel is 99.63 , and the water is 99.46 . The density and temperature values of the liquid are displayed on a 16x2 LCD.

\section{REFERENCES}

[1] G. Popa and B. Pantelimon, "Another method for measuring the density of the liquid in the volume comparator VC1005," in 2013 8TH INTERNATIONAL SYMPOSIUM ON ADVANCED TOPICS IN ELECTRICAL ENGINEERING (ATEE), 2013, vol. d, pp. 1-4. doi: 10.1109/ATEE.2013.6563370

[2] R. Kazys et al., "Ultrasonic density measurement of polymer melts in extreme conditions," in 2013 IEEE International Ultrasonics Symposium (IUS), 2013, pp. 186-189. doi: 10.1109/ULTSYM.2013.0048

[3] M. Heinisch, E. K. Reichel, T. Voglhuber-Brunnmaier, and B. Jakoby, "Characterization and calibration of U-shaped mass density and viscosity sensors by an analytical modeling approach," in 2013 Transducers \& Eurosensors XXVII: The 17th International Conference on Solid-State Sensors, Actuators and Microsystems (TRANSDUCERS \& EUROSENSORS XXVII), 2013, no. June, pp. 1448-1451. doi: 10.1109/Transducers.2013.6627052

[4] B. K. Roy, K. V. Santhosh, R. K. Bharti, and R. Kanthmani, "LabVIEW implementation of liquid density measurement using ultrasonic transducers," in International Conference on Information Communication and Embedded Systems (ICICES2014), 2014, no. 978, pp. 1-4. doi: 10.1109/ICICES.2014.7034194

[5] P. Kielczynski, M. Szalewski, A. Balcerzak, and K. Wieja, "Density and viscosity of liquids determination using an inverse method for Love wave propagation," in 2014 IEEE International Ultrasonics Symposium, 2014, vol. 0, no. 2, pp. 1992-1995. doi: 10.1109/ULTSYM.2014.0496.

[6] T. Manzaneque et al., "Density-viscosity sensor based on piezoelectric MEMS resonator and oscillator circuit," in IEEE SENSORS 2014 Proceedings, 2014, vol. 2014-Decem, no. December, pp. 241-244.

[7] Z. Latifa, M. Ulrich, B. Abdelkader, and H. B. Zakia, "Dynamical behavior and density of the Polymer / Liquid Crystal blends prepared by polymerization induced phase separation," in 2014 North African Workshop on Dielectic Materials for Photovoltaic Systems (NAWDMPV), 2014, pp. 1-4.

[8] H. Antlinger et al., "Ultrasonic piezoelectric tube resonator for physical liquid property sensing," in 2014 IEEE International Ultrasonics Symposium, 2014, pp. 2446-2449.

[9] M. Maroufi and M. Shamshirsaz, "Resonant behavior study of PZT sensor in liquid using PSO method," in 2014 Symposium on Design, Test, Integration and Packaging of MEMS/MOEMS (DTIP), 2014, no. April, pp. 1-4.

[10] M. Heinisch, E. K. Reichel, B. Jakoby, T. Voglhuber-Brunnmaier, and I. Dufour, "Investigation of higher mode excitation of resonant mass density and viscosity sensors," in IEEE SENSORS 2014 Proceedings, 2014, vol. 2014-Decem, no. December, pp. 249-252.

[11] K.-W. Park and H. C. Kim, "High accuracy pressure type liquid level measurement system capable of measuring density," in 
TENCON 2015 - 2015 IEEE Region 10 Conference, 2015, vol. 2016-Janua, no. 2, pp. 1-5.

[12] N. A. Lamberti et al., "A resonant sensor for liquid density measurement based on a piezoelectric bimorph," in 2015 IEEE International Ultrasonics Symposium (IUS), 2015, pp. 1-4.

[13] M. Souza, E. Carvalho, and J. Canuto, "A density and temperature invariant displacer-type liquid level measuring method," in 2018 IEEE International Instrumentation and Measurement Technology Conference (I2MTC), 2018, no. 2, pp. 1-5.

[14] T. V. P. Schut, D. Alveringh, W. Sparreboom, J. Groenesteijn, R. J. Wiegerink, and J. C. Lotters, "Fully integrated mass flow, pressure, density and viscosity sensor for both liquids and gases," in 2018 IEEE Micro Electro Mechanical Systems (MEMS), 2018, vol. 2018 Janua, no. January, pp. 218-221.

[15] J. C. Sanchez-Diaz, J. M. Ramirez-Cortes, P. Gomez-Gil, J. RangelMagdaleno, H. Peregrina-Barreto, and I. Cruz-Vega, "On BernoulliEuler modeling of an immersed beam for axisymmetric container parameters measurement," in 2018 IEEE International Instrumentation and Measurement Technology Conference (I2MTC), 2018, pp. 1-6.

[16] K. Roy, H. Gupta, V. Shastri, A. Dangi, and R. Pratap, "Fluid Density Sensing Using PMUTs,” in 2018 IEEE SENSORS, 2018, vol. 2018-Octob, pp. 1-4.

[17] J.-M. Cabaleiro, T. Paillat, G. Artana, and G. Touchard, "Flow Electrification of Liquids in Rectangular Channels - Comparison of Different Theoretical Models," IEEE Trans. Ind. Appl., vol. 53, no. 6, pp. 5831-5837, Nov. 2017.

[18] M. Gonzalez, H. Seren, E. Buzi, and M. Deffenbaugh, "Fast downhole fluid viscosity and density measurements using a selfoscillating tuning fork device," in 2017 IEEE Sensors Applications Symposium (SAS), 2017, pp. 1-5.

[19] M. A. Dayioglu, "Development of real-time wireless monitoring system for greenhouses: Industrial Bluetooth application," in 2014 22nd Signal Processing and Communications Applications Conference (SIU), 2014, no. Siu, pp. 548-551.

[20] H. Li, H. Xu, J. Wang, X. Fu, and Z. Bai, "Design of Automatic Control System of Coal Sampling Robot Hydraulic System Oil Temperature," in 2017 9th International Conference on Intelligent Human-Machine Systems and Cybernetics (IHMSC), 2017, vol. 1, pp. 38-42. doi: 10.1109/IHMSC.2017.16

[21] Sun Hao and Chi Zongtao, "Design of the environmental temperature and humidity wireless monitoring system," in 2015 12th IEEE International Conference on Electronic Measurement \& Instruments (ICEMI), 2015, vol. 3, pp. 1652-1657. doi: 10.1109/ICEMI.2015.7494529.

[22] D. Parducho et al., "Smart Wound Dressing with Arduino Microcontroller," in 2018 IEEE 10th International Conference on Humanoid, Nanotechnology, Information Technology,
Communication and Control, Environment and Management (HNICEM), 2018, pp. 1-4. doi: 10.1109/HNICEM.2018.8666281.

[23] G. R. Andrei, T. R. Serban, S. V. Alexandru, and B. L. Dorin, "Simulation of traffic management systems using arduino boards," in 2016 8th International Conference on Electronics, Computers and Artificial Intelligence (ECAI), 2016, pp. 1-6. doi: 10.1109/ECAI.2016.7861131.

[24] A. C. Eberendu, B. O. Omaiye, and E. C. Nwokorie, "Using android application to turn smart device into digital microscope on Arduino and Window Platform," in 2017 IEEE 3rd International Conference on Electro-Technology for National Development (NIGERCON), 2017, pp. 508-513. doi: 10.1109/NIGERCON.2017.8281919.

[25] M. Saravanan and A. Das, "Smart real-time meeting room," in 2017 IEEE Region 10 Symposium (TENSYMP), 2017, pp. 1-5. doi: 10.1109/TENCONSpring.2017.8070069.

[26] G. Yang and F. Li, "Investigation of Security and Defense System for Home Based on Internet of Things," in 2010 International Conference on Web Information Systems and Mining, 2010, vol. 2, pp. 8-12. doi: 10.1109/WISM.2010.32

[27] S. Folea, G. Mois, M. Hulea, L. Miclea, and V. Biscu, "Data logger for humidity and temperature measurement based on a programmable SoC," in 2014 IEEE International Conference on Automation, Quality and Testing, Robotics, 2014, pp. 1-4. doi: 10.1109/AQTR.2014.6857877.

[28] E. Raduca, L. Nistor, C. Hatiegan, M. Raduca, I. Padureanu, and S. Draghici, "Web server for command, control and monitoring of industrial equipment," in 2015 9th International Symposium on Advanced Topics in Electrical Engineering (ATEE), 2015, pp. 6166. doi: 10.1109/ATEE.2015.7133673.

[29] F. Jazizadeh and W. Jung, "Personalized thermal comfort inference using RGB video images for distributed HVAC control," Appl. Energy, vol. 220, no. February, pp. 829-841, Jun. 2018. doi: 10.1016/j.apenergy.2018.02.049.

[30] R. R. Pawar and S. B. Deosarkar, "Health condition monitoring system for distribution transformer using Internet of Things (IoT)," in 2017 International Conference on Computing Methodologies and Communication (ICCMC), 2017, no. Iccmc, pp. 117-122. doi: 10.1109/ICCMC.2017.8282650.

[31] S. Abraham and X. Li, "A Cost-effective Wireless Sensor Network System for Indoor Air Quality Monitoring Applications," Procedia Comput. Sci., vol. 34, pp. 165-171, 2014. doi: 10.1016/j.procs.2014.07.090

[32] E. Subin, S. Renuka, K. Chaitanya, and A. Sudheer, "Implementation Of Signal Processing Filters For Portable ECG Devices Using Android Mobile Phone And Bluetooth," in 2017 14th IEEE India Council International Conference (INDICON), 2017, pp. 1-5. doi: 10.1109/INDICON.2017.8487490. 